\title{
Os orçamentos participativos na imprensa regional: um estudo de caso
}

\author{
João Paulo Limão \\ Universidade da Beira Interior \\ E-mail: joao.limao@ubi.pt
}

\section{Resumo}

A informação e comunicação são essenciais para o exercício democrático, independentemente do modelo de democracia. No entanto, no modelo deli-berativo, a partilha e auscultação de diferentes pontos de vista adquire um papel fulcral para o debate e para a tomada de decisões. Nesse sentido, o conjunto de experiências denominadas de Orçamento Participativo (OP), que estabelecem mecanismos de codecisão, com a participação dos cidadãos a determinar o destino de uma percentagem do orçamento público, pode constituir-se como um interessante campo de análise para estudar a impor-tância do acesso à informação para a deliberação. Por outro lado, apesar da crescente afirmação de novos media, nomeadamente digitais, os meios de comunicação tradicionais, como os jornais, a rádio e a televisão continuam a desempenhar um papel fundamental para a formação da imagem que os cidadãos detêm do mundo. Assim, atendendo ao carácter municipal ou local dos OP, pretende-se estudar a publicação de notícias na imprensa regional, a partir de um estudo de caso de um OP municipal deliberativo. O objeto de estudo selecionado é a informação sobre orçamentos participativos publica-da em jornais locais e regionais, a partir do estudo de caso do OP Odemira, que se caracteriza por ser uma das experiências mais antigas em Portugal. Nesta primeira fase de pesquisa, efetuou-se uma análise de conteúdo dos ar-tigos publicados nestes órgãos de comunicação social, com uma abordagem quantitativa ao número de notícias publicadas e às suas características (pe-ríodos de publicação, distribuição por títulos, temas ou fontes). Com esta investigação, pretendeu-se verificar o volume e condições da informação publicada, bem como as temáticas abordadas e as fontes citadas, de modo a entender qual o enquadramento do OP na imprensa regional. Esta análise aos artigos de seis títulos da imprensa local e regional do Alentejo, durante um período de seis anos, correspondentes ao tempo de vida do OP Odemira, permite perceber as fragilidades destas publicações para funcionarem como efetivas esferas públicas, demonstrando-se a escassa presença da sociedade civil como fonte de notícias. Um trabalho que deverá ser prolongado com uma análise mais aprofundada ao discurso das notícias.

Palavras-chave:

Data de submissão: 31/05/2017. Data de aprovação: 30/06/2017.

A Revista Estudos em Comunicação é financiada por Fundos FEDER através do Programa Operacional Factores de Competitividade - COMPETE e por Fundos Nacionais através da FCT - Fundação para a Ciência e a Tecnologia no âmbito do projeto Comunicação, Filosofia e Humanidades (LabCom.IFP) UID/CCI/00661/2013.
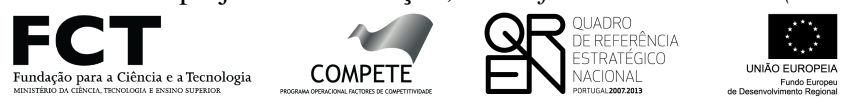

1) 


\begin{abstract}
Information and communication are essential for the democratic process, regardless of the model of democracy. However, in the deliberative model, the sharing and listening of different points of view acquires a central role for debate and decision-making. In this sense, the set of experiences called Participatory Budgeting (PB) which establish with the participation of citi-zens, co-decision mechanisms to determine the destination of a percentage of the public budget, can constitute an interesting field of analysis to study the importance of access to information for deliberation. On the other hand, despite the growing assertion of new media, as digital media, traditional media such as newspapers, radio and television continue to play a key role in shaping citizens' image of the world. Thus, considering the local nature of the $\mathrm{PB}$, we intend to study the news in the local press, based on a case study of a municipal deliberative PB. The selected object of study is the

and regional newspapers, based on the case study of Odemira's PB, one of the oldest of this kind of experience in Portugal. In this first step of the research, a con-tent analysis of the articles published in these media was carried out, with a quantitative approach to the number of news stories published and their characteristics (publication periods, distribution by titles, themes or sour-ces). The goal of this investigation was to verify the volume and conditions of the published information as well as the topics addressed, and the sources cited, to understand the framework of the PB in the local press. This a-nalysis of the articles of six local and regional newspapers in the Alentejo region over a period of six years, corresponding to the lifetime of Odemira's PB, reveals these publications' fragility to function as effective public sphe-res, demonstrating the scarce presence of civil society as a source. A work that should be extended with a deeper analysis of the news discourse.
\end{abstract} in-formation about participatory budget published in local

Keywords: public sphere; media effects; local press; participatory budgeting.

\title{
Introdução
}

IMPLEMENTAÇÃo de mecanismos de maior controlo e decisão por parte das comunidades, com aplicação de passos intermédios como a consulta, parceria ou delegação, e através do ensaio de experiências deliberativas, em diferentes níveis territoriais, como são exemplo os referendos, a ciberdemocracia, júris de cidadãos, mini-públicos selecionados ou orçamentos participativos, tem-se afirmado como uma resposta a algum descontentamento dos cidadãos com o funcionamento das democracias (della Porta, 2013).

No caso concreto dos Orçamentos Participativos (OP), apesar de não existirem definições teóricas estanques, dado que a diversidade de experiências dificulta uma definição única e consensual, procura-se envolver os cidadãos na discussão e decisão das prioridades de orçamentos públicos. Os OP assentam na participação direta dos cidadãos, através de processos de consulta e codecisão, na definição de prioridades de investimento nos orçamentos públicos de um território (Dias, 2008). Nas experiências de OP deliberativos, onde papel decisório cabe aos cidadãos, a comunicação prolonga a sua importância mais do que em op consultivos, por reclamar uma cidadania devidamente informada sobre as diversas possibilidades em debate. Nesse sentido, exige um conjunto de condições para a sua exequibilidade, entre as quais igualdade de condições na participação, afirmação de uma polifonia discursiva e uma auscultação ativa, além do uso da razão. Para bem decidir, os cidadãos devem poder participar no debate e observar a pluralidade de perspetivas, a partir das quais elegerão as melhores propostas para o bem comum, num modelo de esfera pública (Habermas, 2012). 
Os territórios municipais, em virtude da maior proximidade entre cidadãos e destes em relação ao poder local, convidam à experimentação não mediada e à circulação informal de informação, através de conversas face-a-face, em espaços públicos, como expresso no texto seminal de Habermas, ou através de modelos igualmente devedores de uma compressão do espaço na circulação de informação, como cartazes expostos em espaços públicos ou folhetos distribuídos na rua. Mas, muita da vivência pessoal dos cidadãos está limitada a um mapa de percursos estabelecidos - trabalho, habitação, espaços de consumo e diversão, educação e saúde -, fora dos quais, o concelho e mesmo a localidade não são mais do que esboços e sombras. A teia de relações sociais pode alargar um pouco este conhecimento, mas muita da realidade local permanece em zonas de obscuridade. Daí, que também nos territórios municipais, uma parte significativa do conhecimento que os cidadãos têm sobre o local em que vivem resulte de informação mediatizada. Apesar da proliferação da informação na internet, a comunicação social tradicional, como a rádio e imprensa, continua a desempenhar um papel fundamental no acesso dos cidadãos à informação, como acontece com o jornalismo local e regional.

No âmbito da participação e eleições, vários estudos indicam o efeito positivo dos media no acesso à informação e o impacto que pode ter no eleitorado. Baekgard et al. (2014) demonstram que a cobertura mediática de eleições locais, por parte da imprensa regional, tem um efeito positivo sistemático na ida às urnas, bem como a divulgação de notícias de âmbito local, em língua espanhola, junto de comunidades hispânicas nos Estados Unidos da América, contribui para um aumento de voto nas eleições locais, entre elementos destas comunidades (Oberholzer-Gee e Waldfogel, 2009). Também Hayes e Lawless (2015) identificam uma relação entre cobertura noticiosa e participação cidadã, descortinando que a exposição a uma menor cobertura noticiosa de âmbito local deriva numa menor propensão para contactar membros do Congresso, expressar opiniões sobre os candidatos ou votar.

Os meios de comunicação social local cumprem assim um papel informativo na vida local, garantindo um conhecimento essencial para a participação democrática. Este enfoque nas expectativas sobre a imprensa regional como elo de ligação com o local, conforme refere Correia (1998), tem subjacente a esta ideia o entendimento de uma imprensa regional que aborda a "própria vida", entendida como quotidianidade dos públicos, tentando "superar a massificação e a virtualização crescentes resultantes do gigantismo introduzido pela transformação da noção de espaço, tentando voltar a relacionar os assuntos que dizem respeito à polis com a própria vida quotidiana" (Correia, 1998: 6). A comunicação social local e regional comporta assim uma possibilidade de reafirmar a publicidade e racionalidade crítica de uma esfera pública local, aliviada de algumas das contrariedades da esfera pública nacional. Uma oportunidade de revitalização da opinião pública, através da "criação de um espaço público alternativo, na medida em que a proximidade entre a decisão política, o espaço mediático e a vida quotidiana contribuam para anular alguns dos efeitos indesejáveis da massificação dos media" (Correia, 2006: 4).

Os meios de comunicação social local e regional podem assim desempenhar um papel de garante de "exposição transversal" (Mutz, 2006), assegurando que os indivíduos têm acesso a discursos plurais e diversos sobre as diferentes possibilidades em debate, sendo que as condições para a deliberação dos públicos ficam melhor estabelecidas se a informação reportar vozes diver- 
sas, devidamente identificadas e valorizadas, bem como contrastadas em termos de capacidade de resposta (Bennett et al., 2004).

Uma comunicação social local, entendida como "jornalismo de proximidade" (Sousa, 2007), assente no critério geográfico, com o designado "território" (Camponez, 2002) a funcionar como referente, enquanto geografia, cultura e comunidade, conforme patente na Lei de Imprensa $\left(n^{\circ} 2 /\right.$ 99), que determina serem "publicações de âmbito regional as que, pelo seu conteúdo e distribuição, se destinem predominantemente às comunidades regionais e locais". Mas este jornalismo de "proximidade mais próxima", de "informação microscópica" surge subordinado pela intensa interpenetração entre público e privado, com uma dimensão familiar, que abarca um sentimentalismo difuso e uma atitude reverencial (Camponez, 2002). Um jornalismo que pode ser mais pluralista e representativo das diferentes dimensões do local, como anteriormente referido, mas que, pela proximidade, também pode estar mais condicionado. Como salienta Serrano, a pressão "subtil" que se que se exerce sobre o jornalista local "[r]elaciona-se com os laços que se estabelecem normalmente num meio pequeno onde toda a gente se conhece" (Serrano, 2006: 138). Existe como que um "“"nós” territorializado", assente na importância concedida aos êxitos locais e vida associativa, e uma prudência na cobertura de temas conflituantes e desafiadores do poder local. Corre-se um risco de promoção de uma "espiral do consenso" e/ou "espiral do silêncio", com a excomunhão de todas as opiniões distintas (Camponez, 2002: 241). Um jornalismo acrítico que parece omitir qualquer esboço de conflitualidade social e política, onde está ausente o debate, em prol de uma imagem idílica da região (Correia, 2006).

A par desta pressão psicológica, emerge uma dependência económica, resultante da exiguidade dos mercados. As empresas jornalísticas parecem dependentes da publicidade institucional e do poder local, frequentemente o principal anunciante destes jornais (ERC, 2010: 109). Nestas condições, a margem de autonomia dos jornalistas pode estreitar-se, por influência dos poderes politico e económico (Serrano, 2006: 219-245).

Teias de dependência que podem colocar em causa a vitalidade de uma esfera pública local. De acordo com Carvalheiro, nos meios de comunicação social locais, os temas políticos surgem como um exclusivo do poder e partidos políticos, não existindo um debate com a sociedade civil, a qual fica confinada uma inocuidade noticiosa apolítica, sendo que as esferas política e da sociedade civil não se interpenetram (Carvalheiro, 2007). Em parte, na base deste problema pode estar a tendência para o estabelecimento de rotinas de produção jornalística, com a auscultação sistemática das mesmas fontes, que assenta nas diferenças de representatividade e influência, bem como na capacidade de gerar informação relevante (Sousa, 2004). Um fenómeno identificado nos estudos de jornalismo, que se acentua no campo da política, onde as fontes oficiais profissionais são responsáveis por uma percentagem muito elevada das notícias publicadas (Santos, 2006; Ribeiro, 2009). Contudo, um problema maior encontra-se na alegação, por parte de editores e jornalistas, de que o acesso a fontes de informação pode ficar dificultado pela publicação de notícias incómodas para o poder local (ERC, 2010). 


\section{Objeto}

Em Portugal, os orçamentos participativos (OP) surgiram em 2002, numa experiência entretanto descontinuada, reflexo de uma natureza algo volátil das experiências de oP portuguesas, com o aparecimento e desaparecimento frequentes de iniciativas. Mas após um começo débil, o ano de 2006 corresponde a um ponto de viragem na dinâmica dos OP nacionais, com o aparecimento de oito novas experiências. Em simultâneo, depois de uma primeira fase em que os oP nacionais tenderam a um formato essencialmente consultivo, a partir de 2009 começou a verificar-se uma transição para modelos deliberativos (Dias, 2014).

O Orçamento Participativo Odemira desenrola-se neste concelho (distrito de Beja), situado na região do Alentejo, sub-região do Alentejo Litoral, e comporta uma área territorial de 1721 $\mathrm{km}^{2}$. Em termos populacionais, contam-se 26066 habitantes, de acordo com Censos 2011. Tratase de um dos três OP mais antigos em território nacional e, simultaneamente, uma das primeiras experiências deliberativas nacionais, sendo a única com estas características no distrito de Beja. Neste distrito, durante o período analisado, desenvolveram-se apenas OP municipais consultivos em Aljustrel (anos de 2011 a 2015), Almodôvar (2011 e 2012) e Mértola (2011).

Assumindo-se o objetivo de verificar a presença de informação publicada sobre os OP nas páginas dos jornais locais e regionais, tendo como foco o op Odemira, deverá analisar-se a imprensa do distrito de Beja. Segundo dados da ERC, observamos que "o distrito de Beja conta com apenas 9 publicações (1,2\%)" (2010: 33). A maioria são publicações de periodicidade "semanal" $(56,6 \%)$. Segue-se a periodicidade "mensal" (22,2\%), "quinzenário (e/ou bimensal)" (11,1\%) e "online" (11,1\%) (ERC, 2010: 35). A partir de dados nacionais, sobre a imprensa local e regional, ficamos a saber que o universo destes periódicos é bastante desigual, com variação entre publicações de alcance regional e outras de âmbito local, estruturas administrativas e redatoriais em que os papéis comercial e editorial se acumulam e outras em que estão devidamente separados, e entre redações minimalistas compostas por um ou dois jornalistas, e outras que apresentam estruturas mais alargadas e profissionalizadas. Em termos de tiragens e assinantes, a maioria não é auditada (ERC, 2010).

\section{Metodologia}

A exemplo de outros estudos (Serrano, 2006; Correia, 2015), recorreu-se à técnica de análise de conteúdo de artigos publicados, de modo a perceber quais os géneros noticiosos, autoria, atores presentes, fontes das notícias, discurso e temas abordados (Bardin, 2009). Nesse sentido, desenvolveu-se primeiro uma abordagem quantitativa, no sentido de apurar distribuições de números textos publicados, e descortinar as grandes tendências, complementada por uma abordagem qualitativa na análise do discurso das "peças" identificadas, de modo a perceber, com mais detalhe, de que modo os atores surgem referidos no corpo das notícias (Cunha, 2012).

No sentido de promover uma análise de informação publicada na imprensa local e regional sobre o tema "orçamento participativo", a partir do caso específico do OP Odemira, desenvolvido neste concelho do Alentejo Litoral, foram analisados exemplares de seis publicações, desde o aparecimento do OP Odemira até ao momento de estudo (2011-2016), procurando identificar todos 
os artigos informativos e de opinião que abordassem o tema. A nível concelhio escolheram-se os jornais locais Sudoeste (SUD) e Mercúrio (MER), ambos com sede em Odemira, apesar de a sua publicação se ter iniciado em 2014 e 2015, respetivamente, por serem as únicas publicações periódicas neste concelho e por se considerar essencial dispor de periódicos locais para análise, pelo impacto que a dimensão proximidade poderia ter na profusão de artigos e na possibilidade de observação de uma esfera pública local. Num segundo anel de proximidade, enquadrado na área da NUT III "Alentejo Litoral", optou-se por dois títulos: Correio Alentejo (CA) e Litoral Alentejano (LA), apesar de estes não cobrirem integralmente o período em análise. $\mathrm{O} \mathrm{CA}$, apesar de ter sede em Castro Verde (NUT III "Baixo Alentejo"), afirma-se como "um jornal semanário do Baixo Alentejo e Litoral Alentejano", tendo preenchido uma lacuna divulgativa neste território quando não existiam outros periódicos. Uma função também desempenhada pelo LA, com sede em Santiago do Cacém (distrito de Setúbal), cuja publicação foi interrompida em 2011, mas que era uma das poucas publicações a reportar os acontecimentos no Alentejo Litoral, incluindo o concelho de Odemira na sua área de atuação. A nível regional, optou-se pelos títulos Diário do Alentejo (DA) e A Planície (PLA). A opção por estes dois títulos deve-se à integração no distrito de Beja, com sedes em Beja e Moura, compreendidas num raio de $80 \mathrm{~km}$ e $100 \mathrm{~km}$ a partir de Odemira, e, simultaneamente, serem os jornais regionais mais lidos no distrito (ERC, 2010).

\begin{tabular}{|c|c|c|c|c|c|c|c|c|}
\hline Título & Sede & Fundação & Periodicidade & Tiragem & Redação & $\begin{array}{l}\text { Colabo- } \\
\text { radores }\end{array}$ & Páginas & Casos \\
\hline Mercúrio & Odemira & 2015 & mensal & 5000 & 1 a 2 & 7 a 10 & 24 & 19 \\
\hline Sudoeste & Odemira & 2014 & quinzenal & 3000 & 0 & 5 & 16 & 71 \\
\hline $\begin{array}{c}\text { Litoral } \\
\text { Alentejano }\end{array}$ & $\begin{array}{c}\text { Sant. } \\
\text { Cacém }\end{array}$ & 2001 & quinzenal & 2500 & 6 & 7 & 20 & 19 \\
\hline $\begin{array}{c}\text { Correio } \\
\text { Alentejo } \\
\end{array}$ & $\begin{array}{l}\text { Castro } \\
\text { Verde }\end{array}$ & 2006 & $\begin{array}{l}\text { quinzenal, } \\
\text { mens., sem. }\end{array}$ & 3500 & 0 a 4 & 5 & 16 & $\begin{array}{l}170 \\
170 \\
\end{array}$ \\
\hline $\begin{array}{c}\text { Diário do } \\
\text { Alentejo }\end{array}$ & Beja & 1932 & semanal & 6000 & 6 a 7 & 16 & 16 a 40 & 313 \\
\hline A Planície & Moura & 1981 & quinzenal & 3000 & 3 a 5 & 16 & 16 & 143 \\
\hline
\end{tabular}

Numa primeira fase de análise quantitativa ao número de "peças" publicadas, incluímos os seis títulos: SUD (71 exemplares), MER (19), LA (19), CA (170), DA (313) e PLA (143). No entanto, o PLA revelou uma cobertura noticiosa de elevada incidência concelhia, não se tendo identificado nenhum artigo sobre a temática de "orçamento(s) participativo(s)" no período estudado.

\section{Resultados}

1. Ao nível da distribuição, identificámos 125 "peças" jornalísticas em cinco publicações (SUD, MER, LA, CA, DA), entre 1 de janeiro de 2011 e 31 de dezembro de 2016. Em termos de classificação, inspirámo-nos nas categorias estabelecidas por Correia (2015), que comportam quatro "Géneros Informativos": Notícia Breve, Notícia, Reportagem e Entrevista, (Fontcuberta, 2010) e quatro "Géneros Opinativos": Editorial, Coluna/Crónica, Opinião, Cartas dos Leitores, 
aos quais adicionámos uma subcategoria, de género informativo, denominada Notícia Complementar, que, segundo Fontcuberta, "é a que completa outra notícia principal", através de "anedotas, testemunhos directos, recorda factos, cronologias, etc." (Fontcuberta, 2010), que excluímos da análise de frequências, por considerarmos que poderia distorcer a contagem de artigos.

Assim, o conjunto de "peças" de géneros informativos é composto por 117 unidades $(93,6 \%)$, enquanto nos géneros opinativos encontrámos oito $(6,4 \%)$. De acordo com o esperado, o género informativo é claramente predominante. No campo informativo, as notícias são o género mais frequente, com 74 casos $(59,2 \%)$, seguidas das notícias breves, definidas com um máximo de 20 linhas de texto (Sobral e Magalhães, 1999), com 37 casos (29,6\%). A reportagem e a entrevista estão muito menos presentes, contando apenas 3 casos em cada um dos géneros, correspondendo a 2,4\% do total de "peças" em cada caso. No domínio da opinião, o Editorial é o mais abundante, com três exemplos $(2,4 \%)$, os artigos de opinião e a coluna surgem com duas representações $(1,6 \%)$, enquanto nas cartas de leitores se identificou um caso $(0,8 \%)$.

A nível concelhio, verifica-se o predomínio de informação sobre Odemira (n=110, 88\%), seguindo-se "peças" sobre vários concelhos ( $\mathrm{n}=6,4,8 \%)$, Aljustrel $(\mathrm{n}=6,4,8 \%)$, Almodôvar $(\mathrm{n}=2$, $1,6 \%)$ e Beja $(\mathrm{n}=1,0,8 \%)$. Resultados expectáveis, atendendo ao facto de Odemira deter o único OP deliberativo do distrito, além de ser também o único oP da região que continuou a decorrer interruptamente durante os seis anos analisados.

Em termos de progressão cronológica, observa-se uma linha oscilante, com um período inicial de ligeiro, mas progressivo, abrandamento do tema "OP" nas páginas dos jornais, entre 2011 $(\mathrm{n}=16,12,8 \%), 2012(\mathrm{n}=15,12 \%)$ e $2013(\mathrm{n}=14,11,2 \%)$, respetivamente). Em 2014, verifica-se um reavivamento do tema $(n=35,28 \%)$, com nova quebra em $2015(n=20,16 \%)$ e ligeira inversão desta tendência em $2016(n=25,20 \%)$. No entanto, é perfeitamente identificável um ponto de transição em 2014, observando-se que o número de "peças" publicadas no segundo triénio equivale a $64 \%$ do total, além de que se verificou a publicação de um maior número de artigos em todos os anos do segundo triénio em relação aos congéneres do primeiro. Estas oscilações encontram explicações no número de títulos disponíveis e nas alterações de periodicidade de algumas publicações. No primeiro triénio, existiam três publicações em 2011 (CA, DA e LA), das quais o LA desapareceu em novembro de 2011, resultando em apenas duas publicações durante os anos de 2012 e 2013. Acresce que o CA se viu obrigado a reduzir a periodicidade, de semanal para mensal, em setembro de 2012. Em contraste, em 2014 verifica-se o inverso, com o aparecimento do jornal SUD, com sede em Odemira, em fevereiro, e a transição do CA, de mensário para quinzenário, em abril. Deste modo, o concelho de Odemira passava a ter um jornal local na região e, quase em simultâneo, via aumentar a periodicidade de outro. Um ano mais tarde, em 2015, surgia o jornal MER, também sedeado em Odemira, ficando o concelho com dois títulos periódicos em funcionamento simultâneo.

Em termos de distribuição pelos títulos analisados, verifica-se que o CA é o título com maior percentagem de notícias ( $\mathrm{n}=44,35,2 \%)$, seguido do DA $(\mathrm{n}=37,29,6 \%)$ e SUD ( $\mathrm{n}=34,27,2 \%)$. Menos expressivos, o MER conta apenas 7,2\% (n=9) do total e o LA representa $0,8 \%(n=1)$. O PLA fica excluído desta contagem por não se ter identificado nenhuma notícia ou artigo sobre os OP. No entanto, como referimos anteriormente, a volatilidade da existência de alguns destes títulos, aliada às diferenças de periodicidade, convida a uma análise complementar ao número de artigos 
identificados em relação ao número de edições publicadas durante o período analisado. Assim, atendendo à relação entre número de artigos e edições, observamos que o SUD apresenta uma percentagem de 47,89\% ( $n=34)$ nas 71 edições publicadas. Igualmente com números elevados, surge o MER $(n=9,47,37 \%)$. Seguem-se o CA $(n=44,25,88 \%)$, DA $(n=37,11,82 \%)$, e LA $(n=1,5,26 \%)$. Nestes números salienta-se a dimensão de proximidade geográfica, com os títulos sedeados em Odemira a apresentarem um interesse bastante maior na temática dos orçamentos participativos do que os títulos mais distantes. Esta tendência é confirmada na observação das primeiras páginas, nomeadamente em relação ao SUD, em que 35,29\% (n=12) dos artigos sobre o OP têm chamada de primeira página ou manchete. Número consideravelmente superior ao $\mathrm{CA}(\mathrm{n}=8,18,18 \%)$, MER $(\mathrm{n}=1,11,11 \%)$ e DA $(\mathrm{n}=3,8,11 \%)$.

2. A identificação da autoria das peças publicadas pode ser relevante porque esse "indicador pode fornecer elementos sobre a personalização das notícias, ou sobre a responsabilização individual dos jornalistas ou, ainda, sobre a tentativa de maior proximidade com os leitores" (Serrano, 2006: 289). Critérios, nomeadamente o último, que podem contribuir para o fortalecimento da esfera pública, sobretudo através do debate. Por outro lado, pensamos que a assinatura das "peças" pode funcionar como um indicador do tipo de jornalismo praticado. As "peças" não assinadas resultam geralmente de um jornalismo de banca, desenvolvido à secretária, com base em comunicações das fontes, nomeadamente os comunicados de imprensa.

Assim, nos seis anos analisados, encontramos apenas duas reportagens e duas noticias assinadas em 117 peças do género informativo $(3,42 \%)$. Observa-se também que não existe nenhum texto assinado por agência de notícias. A evidência de que os jornalistas não estão identificados na maioria dos textos permite três interpretações: (1) Ao nível dos recursos, os corpos redatoriais são reduzidos e o tempo escasso, o que obriga a um jornalismo de banca, composto sobretudo de notícias curtas e feito a partir de informação pré-fabricada pelas fontes oficiais; (2) Este anonimato pode ser uma estratégia para quebrar as linhas de identificação, que podem ser inibidoras do trabalho jornalístico, libertando os autores de eventuais pressões do meio; (3) Esta circunstância também impede o fortalecimento de uma esfera pública local, tecida a partir da relação que se poderia estabelecer ou reforçar entre jornalistas e a sociedade civil.

3. As notícias e reportagens sobre os orçamentos participativos, publicadas nos jornais locais e regionais do Alentejo caracterizam-se por um discurso emancipatório da cidadania, patente em títulos como "O povo decide!", "Ordem do povo!", "Palavra ao povo", "População faz propostas em Odemira", "População de Odemira participa no orçamento", "Povo (também) decide", "Odemirenses, vocês decidem!" ou "População escolheu!", entre outros exemplos que se podem observar. Tendência que se prolonga no texto das notícias. Escolher, votar, apresentar, decidir são verbos frequentemente conjugados com população, povo, odemirenses, cidadãos. A par da presença dos cidadãos encontra-se a presença do município e do poder local, na figura dos eleitos. No entanto, entre uns e outros existem grandes diferenças. Enquanto os eleitos e os gabinetes oficiais das autarquias são as fontes mais frequentes dos textos das notícias, os cidadãos surgem atribuídos de poderes de decisão, mas excluídos enquanto fontes passíveis de transmitir uma perspetiva sobre estas matérias.

Restringindo a análise das fontes de notícias ao uso de citações diretas (Fontcuberta, 2010), verificamos que entre os 157 textos analisados - a pesquisa incide exclusivamente nos géneros infor- 
mativos, incluindo as notícias complementares (40 casos) - observou-se que 88 "peças" (56,05\%) enquadram discurso direto na sua formulação ou são integralmente compostas de discurso direto. Nestes casos, os municípios são as entidades mais vezes presentes $(n=44,44,50 \%)$. Ainda entre as fontes municipais, mas com especificação do eleito, o discurso dos autarcas surge em 32 ocasiões $(36,36 \%)$. Em relação à sociedade civil, verificamos a presença de discurso de especialistas em 4 ocasiões $(4,55 \%)$ e de cidadãos participantes em processos OP (como proponentes de propostas ou votantes), em 11 ocasiões (12,5\%). Refira-se que as diferentes categorias de atores não se autoexcluem, existindo casos de presença simultânea no mesmo corpo de texto. É notório que é maioritariamente veiculado o discurso oficial, dos municípios e dos eleitos, em contraste com a escassa presença da sociedade civil. O discurso cidadão fica essencialmente remetido para a celebração e apresentação de projetos ganhadores. Esta cobertura jornalística, com celebração dos vencedores, acentua o carácter competitivo da votação, numa importação da dinâmica de "horse race", que se verifica na cobertura de outras votações.

4. No âmbito dos temas abordados nos artigos publicados, contando géneros informativos, incluindo as notícias complementares, e géneros opinativos, identifica-se uma predominância de "peças" sobre o processo do OP $(n=61,48,48 \%)$, seguida por políticas $(n=28,22,4 \%)$ e resultados do OP $(n=17,13,6 \%)$. Menos expressivos, surgem ainda o OP em geral $(n=8,6,4 \%)$, propostas e projetos $(\mathrm{n}=7,5,6 \%)$ e críticas e comentários ao $\mathrm{OP}(\mathrm{n}=4,3,2 \%)$. A partir destes números percebese que a maioria do material publicado é asséptico, limitando-se ao desenrolar do processo, com informação de agenda, com datas de abertura e encerramento, dias de votação e de assembleias participativas, apresentação de resultados, e considerações sobre os objetivos do OP, enunciadas por fontes oficiais. As políticas, aqui classificadas enquanto "peças" que abordam iniciativas, participações ou prémios do município, resultantes do OP, bem como entrevistas e notícias com fontes oficiais a promoverem o OP, surgem com um peso considerável. Já o enunciado de propostas e projetos é menos frequente. Nota final para o escasso debate sobre os OP $(4,85 \%)$ e a inexpressiva presença de críticas e comentários negativos, que se limita a um título (MER), e que demonstram que o debate se encontra ausente das páginas dos jornais consultados.

Conforme anteriormente referido, a propósito das citações de discurso cidadão, em que a sociedade civil surgia essencialmente em momentos de enunciação dos projetos ganhadores, no final do processo, também com a inversão do ângulo de análise, a partir das propostas e projetos em concurso, sucede um fenómeno semelhante. Conforme anteriormente referido, observou-se a quase inexistência de discursos sobre as propostas em votação. Durante o decurso das votações, apenas cinco notícias complementares (3,03\%), em dois títulos - Correio Alentejo e Sudoeste -, mencionam a totalidade das propostas que se encontram em votação. Em análise mais detalhada ao discurso publicado nestes textos, verifica-se que estas cinco notícias complementares, publicadas entre 2014 e 2016, consistem em listagens com o nome das propostas, acompanhadas do valor estimado e, em alguns casos, da freguesia em que se localiza a proposta. Em nenhum dos cinco casos se ultrapassa este formato. Não se verifica nenhum debate acerca de objetivos, vantagens ou desvantagens de quaisquer propostas em relação a outras. Apaga-se qualquer conflitualidade em benefício de uma abordagem conciliatória.

A enunciação de objetivos associados a projetos verifica-se apenas após a votação, em alguns casos no momento de apresentação dos vencedores. Em 2014, fica a saber-se que um dos projetos 
vencedores "visa ajudar pessoas com mobilidade reduzida a praticar desporto" ou que uma ecovia permitirá a "segurança de todos os que circulam a pé e de bicicleta na Estrada Nacional". Outro exemplo, em 2013, explica que a "instalação de oito unidades de microgeração de energia elétrica nos edifícios das entidades públicas das juntas de freguesia" terá efeitos na "redução da pegada ecológica".

\section{Conclusões}

As experiências de orçamentos participativos (OP) deliberativos propõem esquemas de participação cidadã e codecisão sobre as prioridades para os investimentos públicos dos municípios, através de mecanismos em que os cidadãos são chamados a apresentar propostas de investimentos e a votar nas que consideram ser mais válidas para o bem comum. Assim, de modo a que os cidadãos possam decidir conscientemente sobre as propostas a votação é essencial que estes tenham conhecimento sobre as possibilidades em causa, conhecendo essas propostas e os efeitos que poderão ter nas suas vidas, numa dinâmica de esfera pública, em que todos possam proclamar os seus pontos de vista, com a enunciação das possibilidades em debate, e que esse discurso esteja disponível para a auscultação. Nesse sentido, decidimos indagar as páginas de uma amostra de jornais locais e regionais do distrito de Beja, por um período de seis anos, coincidentes com o tempo de vida do OP Odemira.

A pesquisa aqui apresentada constitui-se como uma primeira etapa de um trabalho que deverá ter continuidade e aprofundamento, nomeadamente através de uma análise mais detalhada do discurso publicado. No entanto, estes primeiros resultados permitem estabelecer uma panorâmica geral da presença de informação na imprensa local e regional, deixando patente que os op detêm importância para esta imprensa, sendo motivo frequente de "peças" jornalísticas e mesmo de primeiras páginas, principalmente nas publicações que se localizam no concelho onde decorre o OP Odemira. No entanto, a frequência não encontra paralelo na qualidade da informação, parecendo existir um défice de pluralismo e publicidade crítica. Assim, se é verdade que a sociedade civil é presença como ator em notícias e reportagens sobre o orçamento participativo (OP), no quadro de um discurso emancipatório que afirma a atividade e poder dos cidadãos para "decidir", "participar", "escolher", "apresentar", "escolher" ou "votar", este discurso faz-se quase sempre a partir da voz do poder local, através dos eleitos e dos serviços das autarquias. Os cidadãos, que, através das suas propostas e do seu voto, são os impulsionadores dos OP, estão praticamente excluídos das páginas dos jornais, enquanto emissores de mensagens e fontes das notícias. Esta afonia cidadã impede a participação na esfera pública e num debate deliberativo. Aliás, também uma análise à existência de artigos sobre as propostas em votação, permite perceber que esse debate está quase ausente destas publicações. O máximo que estes jornais se permitem é à apresentação de listagens com a enumeração das propostas que estão a votos, retraindo-se de qualquer apresentação mais detalhada ou argumentação conflitual, e confinando-se a um discurso conciliatório sobre os benefícios dos OP. Existe como que um apagamento da racionalidade crítica.

Em resumo, a afonia cidadã, o reduzido espectro de vozes, com presença maioritária de atores oficiais, ou o apagamento de matérias conflituais, com um discurso essencialmente conciliatório, implicam que algumas das condições fundamentais para a esfera pública não estejam preenchidas. 
No caso em análise, os jornais locais e regionais, apesar de poderem preencher as condições para serem esferas públicas locais, não serão mais do que eventuais "ante-esferas públicas", que eventualmente poderão vir a ser ignificadas noutros espaços.

Estes resultados poderão ser reflexo de algumas características inerentes à comunicação social local e regional, que revela uma existência volátil, economicamente frágil, muito dependente dos poderes locais, com baixos índices de profissionalização, nomeadamente nas redações, e sujeitas a uma pressão de pertença local, que também modela a atuação dos jornalistas e publicações. No entanto, será importante aprofundar esta pesquisa, em termos de análise do discurso, e procurar a sua replicação em geografias distintas, de modo a perceber se serão características exclusivas deste caso ou generalizáveis a outros ambientes.

\section{Bibliografia}

Baekgaard, M. et al. (2014). Local news media and voter turnout. Local Government Studies, 40(4), 518-532.

Bardin, L. (2009). Análise de conteúdo (4th ed.). Lisboa: Edições 70.

Bennett, W. L. et al. (2004). Managing the public sphere: journalistic construction of the great globalization. Journal of Communication, setembro, 437-455.

Camponez, C. (2002). Jornalismo de proximidade. Coimbra: Minerva Coimbra.

Carvalheiro, J. R. (2005). O triângulo bloqueado: media, política e cidadãos na democra-cia local. In J. C. Correia (org.), Comunicação e política (pp.181-202). Covilhã: Estudos em Comunicação - Universidade da Beira Interior.

Correia, J. (1998). Jornalismo regional e cidadania. Bocc - Biblioteca on-line de Ciências da Comunicação. Consultado em julho, 2017, em www.bocc.ubi.pt.

Correia, J. (2006). A imprensa regional e comunicação política. Bocc - Biblioteca on-line de Ciências da Comunicação. Consultado em julho, 2017, em www.bocc.ubi.pt.

Correia, J. (coord.) (2015). Agenda dos cidadãos: jornalismo e participação cívica nos media portugueses. Covilhã: Livros LabCom.

Cunha, I. F. (2012). Análise dos media. Coimbra, Imprensa da Universidade de Coimbra.

della Porta, D. (2013). Can democracy be daved?. Cambridge: Polity Press.

Dias, N. (2008). Orçamento participativo - animação cidadã para a participação pública. N/d: Associação In Loco.

Dias, N. (2014). A decade of participatory budgeting in Portugal: a winding but clarifying path. In N. Dias, Hope for democracy. 25 years of participatory budgeting worldwide (pp. 325-351). São Brás de Alportel: Associação In Loco.

ERC (2010). Imprensa local e regional em Portugal. Lisboa: Entidade Reguladora para a Comunicação Social.

Fontcuberta, M. (2010). A Notícia. Pistas para compreender o Mundo. Alfragide: Casa das Letras. 
Habermas, J. (2012). A transformação estrutural da esfera pública. Lisboa: Fundação Calouste Gulbenkian.

Hayes, D. \& Lawless, J. L. (2015). As local news goes, so goes citizen engagement: media, knowledge, and participation in US house elections. The Journal of Politics, 77 (2), 447-462.

Mutz, D. C. (2006). Hearing the other side: deliberative versus participatory democracy. Nova Iorque: Cambridge University Press.

Oberholzer-Gee, F. \& Waldfogel, J. (2009). Media markets and localism: does local news en Español boost hispanic voter turnout?. American Economic Review, 99 (5), 2120-2128.

Ribeiro, V. (2009). Fontes sofisticadas de informação: análise do produto jornalístico político da imprensa nacional diária de 1995 a 2005. Lisboa: Formal Press.

Santos, R. (2006). A fonte não quis revelar. Um estudo sobre a produção das notícias. Porto: Campo das Letras.

Serrano, E. (2006). Jornalismo político em Portugal. A cobertura de eleições presidenciais na imprensa e na televisão (1976-2001). Lisboa: Edições Colibri.

Sobral, L. \& Magalhães, P. (1999). Introdução ao jornalismo desportivo. N/d: Cenjor e CNID.

Sousa, J. P. (2004). Introdução à análise do discurso jornalístico impresso. Florianópolis: Letras Contemporâneas.

Sousa, J. P. (2007). Comunicação regional e local na Europa Ocidental. Situação geral e os casos português e galego. Bocc-Biblioteca on-line de Ciências da Comunicação. Consultado em julho, 2017, em www.bocc.ubi.pt. 